\title{
Critical appraisal of the 2020 ESC guideline recommendations on diagnosis and risk assessment in patients with suspected non-ST-segment elevation acute coronary syndrome
}

\author{
Evangelos Giannitsis ${ }^{1}$. Stefan Blankenberg ${ }^{2} \cdot$ Robert H. Christenson $^{3} \cdot$ Norbert Frey $^{1} \cdot$ Stephan von Haehling $^{4,5}$. \\ Christian W. Hamm ${ }^{6} \cdot$ Kenji Inoue $^{7} \cdot$ Hugo A. Katus $^{1} \cdot$ Chien-Chang Lee ${ }^{8} \cdot$ James McCord $^{9} \cdot$ Martin Möckel $^{10}$. \\ Jack Tan Wei Chieh ${ }^{11}$ - Marco Tubaro ${ }^{12} \cdot$ Kai C. Wollert ${ }^{13} \cdot$ Kurt Huber $^{14,15}$
}

Received: 18 December 2020 / Accepted: 8 February 2021 / Published online: 26 February 2021

(c) The Author(s) 2021

\begin{abstract}
Multiple new recommendations have been introduced in the 2020 ESC guidelines for the management of acute coronary syndromes with a focus on diagnosis, prognosis, and management of patients presenting without persistent ST-segment elevation. Most recommendations are supported by high-quality scientific evidence. The guidelines provide solutions to overcome obstacles presumed to complicate a convenient interpretation of troponin results such as age-, or sex-specific cutoffs, and to give practical advice to overcome delays of laboratory reporting. However, in some areas, scientific support is less well documented or even missing, and other areas are covered rather by expert opinion or subjective recommendations. We aim to provide a critical appraisal on several recommendations, mainly related to the diagnostic and prognostic assessment, highlighting the discrepancies between Guideline recommendations and the existing scientific evidence.
\end{abstract}

Keywords Guidelines · Critical appraisal · Acute coronary syndromes $\cdot$ Non-ST-segment elevation $\cdot$ High-sensitivity troponin $\cdot$ Diagnosis $\cdot$ Prognosis $\cdot$ Management

Evangelos Giannitsis

evangelos_giannitsis@med.uni-heidelberg.de

1 Medizinische Klinik III, Department of Cardiology,

Angiology and Pulmology, University Hospital of Heidelberg, Im Neuenheimer Feld 410, 69120 Heidelberg, Germany

2 Department of Cardiology, University Heart and Vascular Centre Hamburg, Hamburg, Germany

3 University of Maryland School of Medicine, Baltimore, MD, USA

4 Department of Cardiology and Pneumology, University of Göttingen Medical Center, Göttingen, Germany

5 German Center for Cardiovascular Research (DZHK), Partner Site Göttingen, Göttingen, Germany

6 Department of Cardiology, Kerckhoff Heart and Thorax Centre, Bad Nauheim, Germany

7 Department of Cardiovascular Biology and Medicine, Juntendo University Nerima Hospital, Tokyo, Japan
8 Department of Emergency Medicine, National Taiwan University Hospital, Taipei, Taiwan

9 Henry Ford Heart and Vascular Institute Detroit, Detroit, MI, USA

10 Department of Emergency Medicine, Charité-Universitätsmedizin Berlin, Campus Mitte and Virchow, Berlin, Germany

11 Department of Cardiology, National Heart Centre and Sengkang General Hospital, Singapore, Singapore

12 ICCU, San Filippo Neri Hospital, Rome, Italy

13 Division of Molecular and Translational Cardiology, Department of Cardiology and Angiology, Hannover Medical School, Hannover, Germany

14 3rd Department of Internal Medicine, Cardiology and Intensive Care Medicine, Wilhelminenhospital, Vienna, Austria

15 Medical School, Sigmund Freud University, Vienna, Austria 


\section{Introduction}

In August 2020, the European Society of Cardiology (ESC) presented the Guidelines on NSTE-ACS during the Annual Congress that was held on a virtual platform [1]. These 2020 Guidelines introduced new and revised sections on important topics that differ from the preceding 2015 ESC Guidelines on NSTE-ACS [2]. We believe that some of the new recommendations, which can be anticipated to influence medical decision-making, were not supported by an appropriate level of evidence and are worth reconsidering.

As a global phenomenon, the diagnosis of acute myocardial infarction (AMI) has remained challenging and still chest pain and/or dyspnea are amongst the most prevalent symptoms leading to emergency department (ED) admission in the USA [3]. Accordingly, many EDs face overcrowding as the numbers of patients seeking medical attention for unspecific chest pain are steadily increasing while numbers of patients with confirmed NSTE-ACS have remained stable or are slightly decreasing [4]. Acceleration of patient disposition and facilitation of safe and early discharge have been identified as pragmatic solutions to decongest busy EDs [5]. Therefore, the rationale to advance the use of hs-cTn assays and to further instigate the implementation of faster diagnostic algorithms has to be appreciated. Moreover, guidelines endorse measures for a more convenient, user-friendly interpretation of cTn results such as the recommendation to abstain from age-, sex-, or comorbidity-adapted decision cutoffs although the use of sex-specific cutoffs has been endorsed by the 4th version of the Universal Definition of Myocardial Infarction (UDMI). Other practical recommendations are given to overcome infrastructural barriers in the hospitals such as delayed laboratory reporting.

Therefore, this expert opinion article highlights strengths of the 2020 ESC NSTE-ACS Guidelines but also indicates limitations, where the recommendations are open to question in the light of inconsistent or absent evidence.

\section{Critical appraisal of the guidelines}

\section{Strengths of 2020 ESC guidelines}

Overall, the guideline authors must be congratulated for creating an extensive and comprehensive update of the preceding 2015 ESC Guidelines on acute coronary syndromes [2] without ST-segment elevations (NSTE-ACS). As a consequence of the accumulated evidence regarding the efficacy and safety of accelerated diagnostic protocols, new recommendations were introduced regarding the diagnostic strategies.
ESC $0 / 1 \mathrm{~h}$ protocol endorsed as the preferential diagnostic strategy

While the 2011 ESC [6] and 2015 ESC guidelines [2] endorsed the ESC $0 / 3 \mathrm{~h}$ protocol whenever hs-cTn assay were available in clinical routine, the 2020 ESC guidelines [1] now recommend to use the ESC $0 / 1 \mathrm{~h}$ protocol preferentially over the ESC $0 / 3 \mathrm{~h}$ protocol. Supportive evidence comes from several independent observational studies, a randomized controlled trial (RCT) from Australia [7], two real-world evidence studies $[8,9]$, and a meta-analysis from 15 trials that include 11,014 patients [10] that have conferred robust evidence on efficacy and safety of the ESC $0 / 1 \mathrm{~h}$ protocol. Besides the excellent discriminatory ability to rule out a NSTEMI, findings corroborate the safety of discharge after rule out of patients deemed to be at low risk [7-10]. One study shows higher discharge rates without increased utilization of coronary angiography, coronary interventions, cardiac stress, or imaging procedures [11]. The promotion of the ESC $0 / 1 \mathrm{~h}$ algorithm is further fostered by findings on reduced length of observation time and overall length of stay in ED, and lower hospital costs [12]. However, in the past, concerns were also expressed regarding the universal use of the ESC 0/1 h algorithm, mainly based on doubts regarding the accuracy of very small concentration changes, the limited evidence on early presenters, and uncertainties about the accuracy of rule-in using short re-testing intervals [13]. In full awareness that fast protocols are adopted slower than projected [14], the authors suggested solutions to overcome laboratory delays from blood draw to reporting, an issue presumed to represent the most important obstacle for worldwide implementation of fast diagnostic protocols. Therefore, the authors added a paragraph with a corresponding illustration proposing how to facilitate the diagnostic process by collection of blood at fixed intervals of $60 \mathrm{~min}$ without awaiting the report of the first blood draw. This strategy has the advantage of an optimal implementation of the ESC $0 / 1 \mathrm{~h}$ protocol. On the other hand, many perceive the additional costs and unnecessary blood collection anticipated in $30 \%$ of low-risk patients who could have been ruled out by a single very low hs-cTn value $<\mathrm{LoD}$ at presentation as a relevant disadvantage of such a recommendation [15].

\section{Deferred use of gender-, age- and other comorbidity-adjusted diagnostic cutoffs}

There is an ongoing discussion on the importance of gender-, age-, or comorbidity-adapted decision cutoffs [16]. Beyond doubt and supported by findings from sophisticated cardiac imaging and cardiac function tests [17], hs-cTn concentrations were found to be lower in healthy women than in men resulting in a lower 99th percentile upper limit of normal 
(ULN) in women [18]. Likewise, concentrations increase with advancing age due to age-related subclinical comorbidities even in the absence of objective cardiovascular morbidity or renal impairment [19]. Since symptomatic patients presenting to an ED are usually older than the average age in healthy reference populations and are rarely healthy, there is a debate around the usefulness of a general uniform 99th percentile ULN. Concentrations of hs-cTn increase with age and comorbidities decreasing the numbers of patients with hs-cTn concentrations below the 99th percentile ULN on admission [20]. Hence, use of a low diagnostic threshold at the uniform 99th percentile is associated with a very high sensitivity but low clinical specificity and positive predictive value. The 4th Universal Definition of Myocardial Infarction (UDMI) recommended the use of sex-specific upper reference limits (URL, 99th percentiles) and the ESC endorsed the 4th UDMI [21]. Thus, the ESC 2020 Guidelines [1] should recommend using different 99 th percentiles cutoffs for men and women. Surprisingly, this it is not the case. The authors justify this discrepancy between actual ESC documents with their clinical experience that a "mixture" of different ULN will confuse the clinicians' judgement. Although, the 4th version of the UDMI [21] advocates the use of serial troponin measurements to discriminate chronic from acute myocardial injury, not all women having small hs-cTn increases, who are evaluated with a sex-independent ULN, may be correctly classified. While this issue may not be relevant for hs-cTnT [22] and some hs-cTnI assays, previous trials found a relevant diagnostic and prognostic reclassification in women with the Abbott Architect hs-cTnI assay [23]. With this assay, the difference between men and women is nearly two times larger than for hs-cTnT. Thus, the actual NSTE-ACS guidelines are in a partial conflict with 4th version of UDMI and might disadvantage women.

\section{Increasing importance of high-sensitivity point-of-care troponin tests with designation for rule out}

Until recently, point-of-care (POC) tests were recommended only in settings where central laboratory assays were not available, or when turn-around-times (TAT) exceeded 45-60 min. Due to an insufficient analytical sensitivity and precision of POC technologies, cTn testing on POC devices used to be utilized as an aid for rule-in of a NSTEMI, but its use for a reliable rule out of NSTEMI was discouraged [24]. The LSI Medience Pathfast hs-cTnI assay (formerly Mitsubishi Pathfast) meets high-sensitivity criteria [25], received approval by the FDA for use in clinical laboratory or POC settings [26], has been validated for the ESC 0/1 h protocol [27], and is also recommended in the 2020 ESC guidelines [1]. In perspective, several reports indicate a similar performance of other POC hs-cTnI tests and suggest that these assays could emerge as alternatives to centralized laboratory hs-cTn testing in the near future [27-30]. The shorter TAT with POC testing makes this technology more appealing as many patients can have AMI excluded at presentation or within $1 \mathrm{~h}$.

However, several shortcomings should dampen the enthusiasm about POC testing including lack of evidence, despite the existing publications, that POC systems truly work in a real-world clinical practice when tests are run $24 \mathrm{~h} / 7$ days by non-laboratory personnel and using whole blood as material. In addition, the effect of analytical issues has not been addressed completely so far [29].

Finally, it is important to indicate that the list of available POC troponin assays is incomplete regarding cutoffs and concentration changes for several new hs-cTnI assays using the ESC $0 / 2 \mathrm{~h}$ protocol, and information on commercially available assays is not updated since it maintains the Singulex assay that it is not operational since 1 year.

\section{New definition for high-sensitivity designation of cardiac Troponin assays}

After the introduction of cTn assays with improved analytical sensitivity and precision, it became apparent that there were no agreed upon criteria to define the high-sensitivity designation. The scorecard criteria proposed by Fred Apple were reasonable as they combined analytical and clinical criteria [31]. Accordingly, cTn assays were attributed a hscTn designation if they were able to measure cTn at or below the 99th percentile value of a healthy reference population with a total imprecision of less than $10 \% \mathrm{CV}$, and were able to detect cTn in at least $50 \%$ of healthy individuals. This suggestion was refined by the International Federation of Clinical Chemistry (IFCC) and Laboratory Medicine Task Force on Clinical Applications of Bio-Markers (IFCC TF-CB) introducing the requirement to measure $\mathrm{cTn}$ concentrations above the limit of detection in 50\% of men and women [32]. Unfortunately, reference populations with a sample size large enough to allow the calculation of sex-specific cutoffs are sparse, and many manufacturers have no access to appropriately sized sample banks. Now, the 2020 ESC guidelines [1] softened the IFCC criteria by eliminating the requirement for detection of cardiac troponin in at least $50 \%$ of both genders, presumably to facilitate the faster implementation of commercially available cTn assays with high-sensitivity designation [1]. Only in the POC paragraph a 50 to $95 \%$ rate of measurements above the LoD is briefly mentioned. However, at that point, a discussion should be initiated about standardized criteria for the validation of new hs-cTn assays and diagnostic algorithms before their entry in Guidelines. 


\section{Controversies and uncertainties}

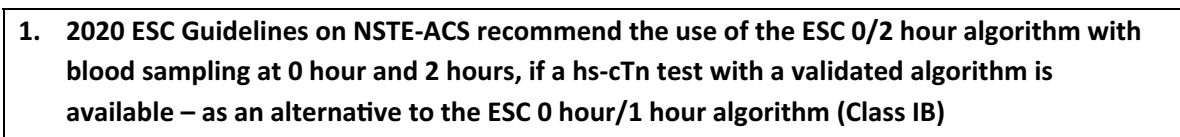

The 2020 ESC Guidelines recommend a novel ESC $0 / 2 \mathrm{~h}$-algorithm as the preferred alternative to the ESC 0/1 h-algorithm in the early triage of suspected acute myocardial infarction This algorithm is similar to the ESC 0/1 h algorithm and uses distinct thresholds for baseline concentrations and change value for a re-testing at $2 \mathrm{~h}$. The algorithm contains a strategy for immediate rule out based on a single low hs-cTn concentration at baseline and requires serial measurements two hours apart. While the two strategies combined in the novel algorithm have been derived and validated separately, the entire ESC $0 / 2 \mathrm{~h}$ algorithm has not been validated, yet. Distinct to the Accelerated Diagnostic Protocol (ADP) $0 / 2 \mathrm{~h}$ protocol, the ESC $0 / 2 \mathrm{~h}$ algorithm does not require a clinical score, i.e. the TIMI score to achieve an acceptable safety.

Five publications [33-37] were discussed to support this recommendation. Neumann et al. [33] prospectively evaluated individual patient-level data from 15 studies including 23,327 patients who presented to the emergency department with suspected acute myocardial infarction (AMI). The validation cohort on 13,047 patients included a 2-h hscTn-based ADP algorithm from Australia (summarized as ADAPT-BSN) and New Zealand (summarized as ADAPT$\mathrm{CH})$. Thus, while this study nicely supports the usefulness of fast diagnostic protocols with repeat sampling within $210 \mathrm{~min}$, there is no obvious reason to restrict the recommendation to the ESC $0 \mathrm{~h} / 2 \mathrm{~h}$ protocol and not to extend the recommendations to the hs-cTn-based 2-h ADP protocol, as well. Boeddinghaus et al. [34] compared the diagnostic accuracy, quantified by the area under the receiver operating curve (AUC), of the Siemens-hs-cTnI-Centaur assay versus the two established hs-cTn assays (Roche-hs-cTnT-Elecsys, Abbott-hs-cTnI-Architect). In addition, the investigators developed a diagnostic algorithm for the new Siemens Centaur assay for the ESC $0 \mathrm{~h} / 1 \mathrm{~h}$ and ESC $0 \mathrm{~h} / 2 \mathrm{~h}$ protocols. The derivation cohort for the hs-cTnI Siemens Centaur ESC $0 \mathrm{~h} / 1 \mathrm{~h}$ algorithm was randomly selected among patients with an available blood sampling set at $0 \mathrm{~h}$ and $1 \mathrm{~h}$. For the derivation set for the ESC $0 \mathrm{~h} / 2 \mathrm{~h}$ algorithm patients were randomly selected in a 2:1 ratio to ensure a sufficient number of patients. Validation was executed in the same cohort but not in an independent external cohort. Optimal thresholds for rule out were selected to allow for maximal sensitivities and negative predictive values (NPVs) of $99 \%$ and were not based on package insert-specified thresholds. Optimal thresholds for rule-in were obtained based on a classification and regression tree (CART) analysis targeting a minimal positive predictive value (PPV) of $70 \%$. While the performance of the ESC $0 \mathrm{~h} / 1 \mathrm{~h}$ and ESC $0 \mathrm{~h} / 2 \mathrm{~h}$ algorithm was studied for the new hs-cTnI Siemens Centaur in the derivation and validation set, with the Roche hs-cTnT and Abbott Architect hs-cTnI serving as reference, it was not within the scope of this study to compare the ESC $0 \mathrm{~h} / 1 \mathrm{~h}$ and ESC $0 \mathrm{~h} / 2 \mathrm{~h}$ algorithms. Thus, both algorithms have not been compared directly.

Reichlin et al. [35] analyzed the diagnostic accuracy of absolute delta $(\Delta)$ and relative (\%) changes of cTn among 836 patients presenting to the emergency department with symptoms suggestive of AMI. Blood samples for the determination of high-sensitive cTnT and Siemens cTnI ultra were collected at presentation and after 1 and $2 \mathrm{~h}$. The AUC for diagnosing AMI was significantly higher for 2-h absolute $(\Delta)$ versus 2 -h relative $(\%)$ cTn changes. The authors concluded that absolute changes of cTn levels have a significantly higher diagnostic accuracy for AMI than relative changes and seem, therefore, to be the preferred criteria to distinguish AMI from other causes of cTn elevations.

Hence, neither the performance of hs-cTn in general nor the relative performance of the ESC $0 \mathrm{~h} / 1 \mathrm{~h}$ versus the ESC $0 \mathrm{~h} / 2 \mathrm{~h}$ was evaluated in this publication, raising the question why this article was referenced in the Guidelines to support a $0 \mathrm{~h} / 2 \mathrm{~h}$ algorithm as an alternative to the ESC $0 \mathrm{~h} / 1 \mathrm{~h}$ algorithm. Boeddinghaus et al. [36] developed an algorithm for the use of the Abbott Architect hs-cTnI assay in 1,435 patients using a derivation cohort from the Advantageous Predictors of Acute Coronary Syndrome Evaluation (APACE) study, and was consecutively validated for diagnostic accuracy in 1,194 patients from the 2-h Accelerated Diagnostic Protocol to Assess Patients With Chest Pain Symptoms Using Contemporary Troponins as the Only Biomarker (ADAPT) trial. Optimal thresholds for rule out were selected to allow for a maximal diagnostic sensitivity and NPV of $99 \%$. Optimal thresholds for rule-in were selected to allow for the highest diagnostic specificity and positive predictive value (PPV). Diagnostic sensitivity and NPV were $98.7 \%$ and $99.7 \%$ for rule out, specificity and PPV were $97.4 \%$ and $82.2 \%$ for rule-in, respectively. Thirty-day survival was $100 \%$ for rule out patients in both cohorts. This 
study provides evidence supporting the safe use of a $0 \mathrm{~h} / 2 \mathrm{~h}$ algorithm based on the Roche hs-cTnT and the Abbott Architect hs-cTnI assays. The algorithm was validated in an external independent cohort showing comparable performance. As such this article is valid to support the usefulness of $0 \mathrm{~h} / 2 \mathrm{~h}$ algorithm, but does not provide information on its performance relative to the ESC $0 \mathrm{~h} / 1 \mathrm{~h}$ or the ESC $0 \mathrm{~h} / 3 \mathrm{~h}$ algorithms.

Nestelberger et al. [37] investigated an algorithm for the use of the ACCESS hs-cTnI (Beckman Coulter). The authors used 1,131 patients of a derivation cohort from the APACE study. The algorithm was consecutively validated for diagnostic accuracy externally in 1,280 patients from two studies using similar inclusion and exclusion criteria, namely the Accelerated Diagnostic Protocol to Assess Patients with Chest Pain Symptoms Using Contemporary Troponins as the Only Biomarker (ADAPT) and the Improved Assessment of Chest Pain Trial (IMPACT). Findings in the derivation and validation studies demonstrated safety and efficacy of the hs-cTnI-Access 0/2-h algorithm for rule out or rule-in of AMI. This study confers evidence for the usefulness of a $0 / 2 \mathrm{~h}$ algorithm but does not provide information on the relative performance of the $0 / 2 \mathrm{~h}$ algorithm compared to ESC $0 \mathrm{~h} / 1 \mathrm{~h}$ or ESC $0 \mathrm{~h} / 3 \mathrm{~h}$ algorithm.

Thus, consistent with 2020 ESC NSTE-ACS Guidelines [1], overall evidence supports a class IB recommendation for the ESC $0 \mathrm{~h} / 2 \mathrm{~h}$ algorithm with the advantage that findings from observational studies were validated in external independent cohorts. Unfortunately, evidence supporting the effectiveness and safety of hs-cTn-based ADP protocols was not appropriately indicated leading to a disadvantage of the latter.

\section{Underappreciation of the hs-cTn based ADP $0 / 2 \mathrm{~h}$ algorithms}

Algorithms were developed based on hs-cTn results at admission and $2 \mathrm{~h}$ to further shorten evaluation time. These algorithms apply data-driven cutoffs not reflecting assay performance or biological plausibility, and incorporate specific $(\Delta)$ values. However, these alternative fast diagnostic strategies were not recommended as an alternative to the ESC $0 \mathrm{~h} / 1 \mathrm{~h}$ or ESC $0 \mathrm{~h} / 2 \mathrm{~h}$ protocols although there is abundant scientific evidence to support a class IB recommendation for ADP protocols, as well. Supportive evidence for the diagnostic performance of ADPs using hs-cTn with sampling at admission and $2 \mathrm{~h}$ is summarized in a review article by Eggers et al. [38].

The ADAPT trial investigated an ADP that was built on a TIMI risk score of 0, non-ischemic ECG, and nonincreased cTn results at admission and at $2 \mathrm{~h}$ [39]. In studies using hs-cTn assays, the ADAPT-ADP provided a $100 \%$ sensitivity regarding 30-day MACE, but only 19.6-32.3\% of the patients qualified for rule out. Modifying the ADP by including a TIMI score of 1 increased the rule out group to $29.8-41.5 \%$ at the expense of lower prognostic sensitivities (94.1-100\%). Another critical point of this study is that no events occurred at all and, therefore, this study could have had significant selection bias or an error in the design.

The Emergency Department Assessment of Chest Pain Score (EDACS) integrates information on weighted variables (demographics, risk factors, symptom characteristics) [40]. The EDACS-ADP uses an EDACS score of 16 points, a non-ischemic ECG, and normal cTn concentrations at admission and at $2 \mathrm{~h}$ to identify patients eligible for early rule out. In a randomized head-to-head comparison with the ADAPT-ADP $(n=558)$, the EDACS-ADP pathway has been shown to identify more low-risk patients $(47.7 \%$ vs $32.3 \%)$ while providing high safety with a sensitivity of $100 \%$ for survival. [41]. A randomized trial on 544 patients with suspected ACS randomized patients to a rapid diagnostic pathway or a standard care to test the effectiveness defined as discharge from hospital within $6 \mathrm{~h}$ without a major adverse cardiac event occurring within 30 days [42]. The impact of this randomized trial [42] on the strength of recommendation class and level of evidence was not appropriately addressed by the 2020 ESC Guidelines [1].

Wildi K et al. [43] directly compared the ADP 2-h protocol against the ESC $0 / 2 \mathrm{~h}$ protocol only for rule out (but not for rule-in) in two independent cohorts, namely the APACE study and the ADAPT trial. Both algorithms provided very high and comparable safety as quantified by the NPV and sensitivity for AMI and major adverse cardiac events (MACE) at 30 days in patients triaged toward rule out. The percentage of patients triaged toward rule out was significantly lower with the 2-h ADP (36-43\%) versus the ESC 2-h algorithm (55-68\%) with both assays and in both cohorts $(p<0.001)$. The sensitivity of the 2-h ADP was higher for 30-day major adverse cardiovascular events. The ESC 2-h algorithm was more efficient but not all patients ruled out for AMI by this algorithm were appropriate candidates for early discharge. Accordingly, the authors concluded that the 2-h ADP seems superior in the selection of patients for early discharge from the ED. Although this study cannot be regarded as appropriate for a recommendation of effectiveness across the entire diagnostic spectrum of suspected ACS, at least the favorable findings on the 2-h hs-cTn ADP algorithm raise the question why these study findings were excluded from the evidence-based recommendation process.

In summary, the substantial evidence supporting hs-cTnbased ADP protocols including the presence of positive findings from a randomized trial was not appropriately reflected by the 2020 ESC NSTE-ACS Guidelines [1]. Neither the existing evidence nor findings from a randomized trial [42] supporting a hs-cTnI based 2-h ADP was reported. In addition, the Guidelines did not mention unfavorable findings 
with ESC 0/2 $\mathrm{h}$ algorithm compared to the 2-h ADP from a study that directly compared strategies, with a restricted focus on rule out alone [43].

Thus, it appears that almost all recommendations and protocols have been derived from evidence based on the APACE registry while other alternative evidences were largely omitted. both hs-cTnT and hs-cTnI. The relevance of this article for the ESC recommendation is controversial for two reasons: (a) the investigators focused on the rule-out part only, but did not evaluate the complete diagnostic process that incorporates rule-in AND rule out, as well as an observational zone that is exclusive to the ESC $0 \mathrm{~h} / 1 \mathrm{~h}$ algorithm; (b) because the significant difference between ESC $0 \mathrm{~h} / 1 \mathrm{~h}$ and

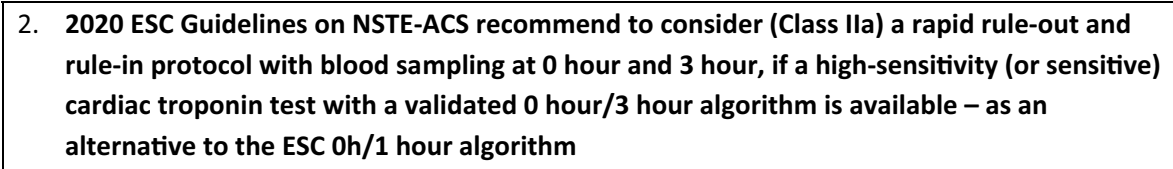

The 2015 ESC NSTE-ACS Guidelines [2] recommend use of the ESC $0 \mathrm{~h} / 3 \mathrm{~h}$ algorithm based on several large observational studies that conferred evidence beyond doubt on the superiority of the ESC $0 \mathrm{~h} / 3 \mathrm{~h}$ algorithm over the standard protocol with blood sampling at $0 \mathrm{~h}$ and $6-9 \mathrm{~h}$ in the absence of a high-sensitivity cardiac troponin assay. Four publications are now cited to support the assigned class IIa (LOE B) recommendation, i.e. to prioritize the ESC 0hour/ $1 \mathrm{~h}$ algorithm over the ESC $0 \mathrm{~h} / 3 \mathrm{~h}$ protocol [44-47]. These references are likely to fuel a controversial debate as they do not unequivocally support the assigned class of recommendation. The article by Wildi et al. [44] evaluated the performance of the ESC $0 \mathrm{~h} / 3 \mathrm{~h}$ protocol using four different high-sensitivity cTn assays. The 3-h rule-out protocol correctly diagnosed 99.9\% (95\% CI 99.1-100\%), 99.5\% (95\% CI 98.3-99.9\%), 100\% (95\% CI 98.1-100\%), and $100 \%$ (95\% CI $98.2-100 \%)$ of early presenters (<6 h from chest pain onset) supporting a high recommendation class for the ESC $0 \mathrm{~h} / 3 \mathrm{~h}$ over the "old" ESC standard protocol with blood sampling at $0 \mathrm{~h}$ and re-testing after 6-9 $\mathrm{h}$. However, this article does not provide any data that compare the ESC $0 \mathrm{~h} / 1 \mathrm{~h}$ or ESC $0 \mathrm{~h} / 2 \mathrm{~h}$ protocols with the ESC $0 \mathrm{~h} / 3 \mathrm{~h}$ protocol. Hence, citation of this article in this context seems inappropriate.

Badertscher et al. [45] directly compare the efficacy and safety of the ESC $0 \mathrm{~h} / 3 \mathrm{~h}$ algorithm with the ESC $0 \mathrm{~h} / 1 \mathrm{~h}$ algorithm for rule out of a MI using the Roche hs-cTnT and the Abbott Architect STAT hs-cTnI assays. The negative predictive values for the ESC $0 \mathrm{~h} / 1 \mathrm{~h}$ algorithm are significantly lower than those for the ESC $0 \mathrm{~h} / 3 \mathrm{~h}$ protocol using the Abbott Architect hs-cTnI. The NPVs for the ESC $0 \mathrm{~h} / 3 \mathrm{~h}$ protocol are similar with the ESC $0 \mathrm{~h} / 1 \mathrm{~h}$ algorithm when using the hs-cTnT assay. A significantly higher proportion of patients qualifying for rule out was demonstrated for the $\mathrm{ESC} 0 \mathrm{~h} / 1 \mathrm{~h}$ algorithm versus the ESC $0 \mathrm{~h} / 3 \mathrm{~h}$ protocol with
ESC $0 \mathrm{~h} / 3 \mathrm{~h}$ is restricted to a higher rate of patients in the rule-out pathway, and at least for the hs-cTnT assay a similar performance for the safety of rule out is demonstrated.

The third article by Chapman et al. [46] compared the diagnostic performance of three rapid diagnostic protocols, namely the High-STEACS pathway, the ESC $0 \mathrm{~h} / 1 \mathrm{~h}$, and the ESC $0 \mathrm{~h} / 3 \mathrm{~h}$ protocols in a retrospective analysis. All three protocols were compared regarding sensitivities, specificities, negative and positive predictive values using the new Atellica IM hs-cTnI assay (Siemens Healthineer) from frozen samples. Briefly, the NPVs of all three strategies were between 98 and $99.5 \%$, highest for the High-STEACS pathway and lowest for the ESC $0 \mathrm{~h} / 3 \mathrm{~h}$ protocol. Sensitivities were considerably lower for all three strategies ranging from 90.8 to $92.2 \%$ for the ESC $0 \mathrm{~h} / 3 \mathrm{~h}$ and ESC $0 \mathrm{~h} / 1 \mathrm{~h}$ to $98 \%$ for the High-STEACS pathway. Specificities and PPVs were disappointingly low for all pathways, with the exception of a specificity of $98.2 \%$ for the ESC Ohour $/ 1 \mathrm{~h}$ protocol. This comparative study was limited by three shortcomings: (a) it was retrospective evaluation; (b) the cutoffs of 3 and $5 \mathrm{ng} / \mathrm{L}$ for new Atellica IM hs-cTnI assay (Siemens) were transferred from a different study using hs-TnI concentrations measured by the Abbott Architect systems; (c) all measurements were conducted by Siemens Healthineers, and thus relevant conflicts of interest exist, which should preclude this study from being used in the Guidelines.

The fourth article by Chapman et al. [47] compared the performance of the High-STEACS pathway with the ESC $0 \mathrm{~h} / 1 \mathrm{~h}$ protocol on 1,218 patients with suspected ACS. Briefly, this study is interesting but does not add any information on the superiority of the ESC $0 \mathrm{~h} / 1 \mathrm{~h}$ protocol because this study compared the High-STEACS pathway, with blood sampling at $0 \mathrm{~h}$ and $3 \mathrm{~h}$ with the ESC $0 \mathrm{~h} / 3 \mathrm{~h}$ protocol. 


\section{The 2020 ESC Guidelines do not recommend to routinely measure additional biomarkers (class IIIB) such as h-FABP or Copeptin, in addition to hs-cTn - for initial diagnostic purposes.}

This class IIIB recommendation is most critical as it implies that other diagnostic biomarkers perform inferior or might even harm. Therefore, such a recommendation class should be supported by robust evidence, particularly when previous ESC guidelines [2] recommended using additional biomarkers, and because neither hs-cTn assays nor fast diagnostic protocols have been implemented broadly, at the moment [14].

\section{Copeptin for instant rule out of MI}

Copeptin is the molecule including the 39 aa carboxy-terminal (CT) sequence of the pro-vasopressin molecule and it is considered a non-specific biomarker with rapid increase in AMI in blood while cTn or hs-cTn levels are still normal, termed the "troponin-blind period" [54]. CT pro-vasopressin (Copeptin) as a marker of vasopressin reflects the immediate physiological response to arterial under-filling in AMI, when the cardiac output decreases in minutes after epicardial vessel closure. Commonly, this phenomenon is addressed as "cardiovascular stress". The 2020 ESC NSTE-ACS guidelines [1] suggest that low Copeptin concentrations below the decision cutoff could improve the negative predictive value (NPV) of cTn for ruling out patients presenting early after symptom onset when cTn is not elevated in the first blood sample [1]. Conversely, a positive Copeptin while cTn or hs-cTn is below the 99th percentile URL suggests a strict serial troponin strategy. Despite increasing evidence [48-51] supporting that Copeptin accelerates the rule out of MI when combined with a hs-cTn assay (Fig. 1), ESC guidelines endorse the use of Copeptin as an alternative only when sensitive or high-sensitivity cardiac troponin assays are not available. This contrast with 2015 ESC Guidelines [2] that state that "Copeptin may have some added value even over high-sensitivity cardiac troponin in the early rule out of MI". Recently, Wildi et al. [59] reported on the performance of 14 rule-out strategies in patients admitted with suspected NSTE-ACS. A dual marker strategy (DMS) combining Copeptin with hs-cTn was associated with the worst performance amongst all strategies for rule out in terms of sensitivities and NPVs, and was associated with the highest event rates within 90 days. However, it is important to indicate that DMS was tested retrospectively across the entire study cohort and did not exclude high-risk patients, as recommended [48, 49]. A substudy from TRAPID-AMI [55] investigating the role of Copeptin combined with hs-cTn elegantly demonstrated that exclusion of high-risk patients resulted in $100 \%$ sensitivity and $100 \% \mathrm{NPV}$, without any

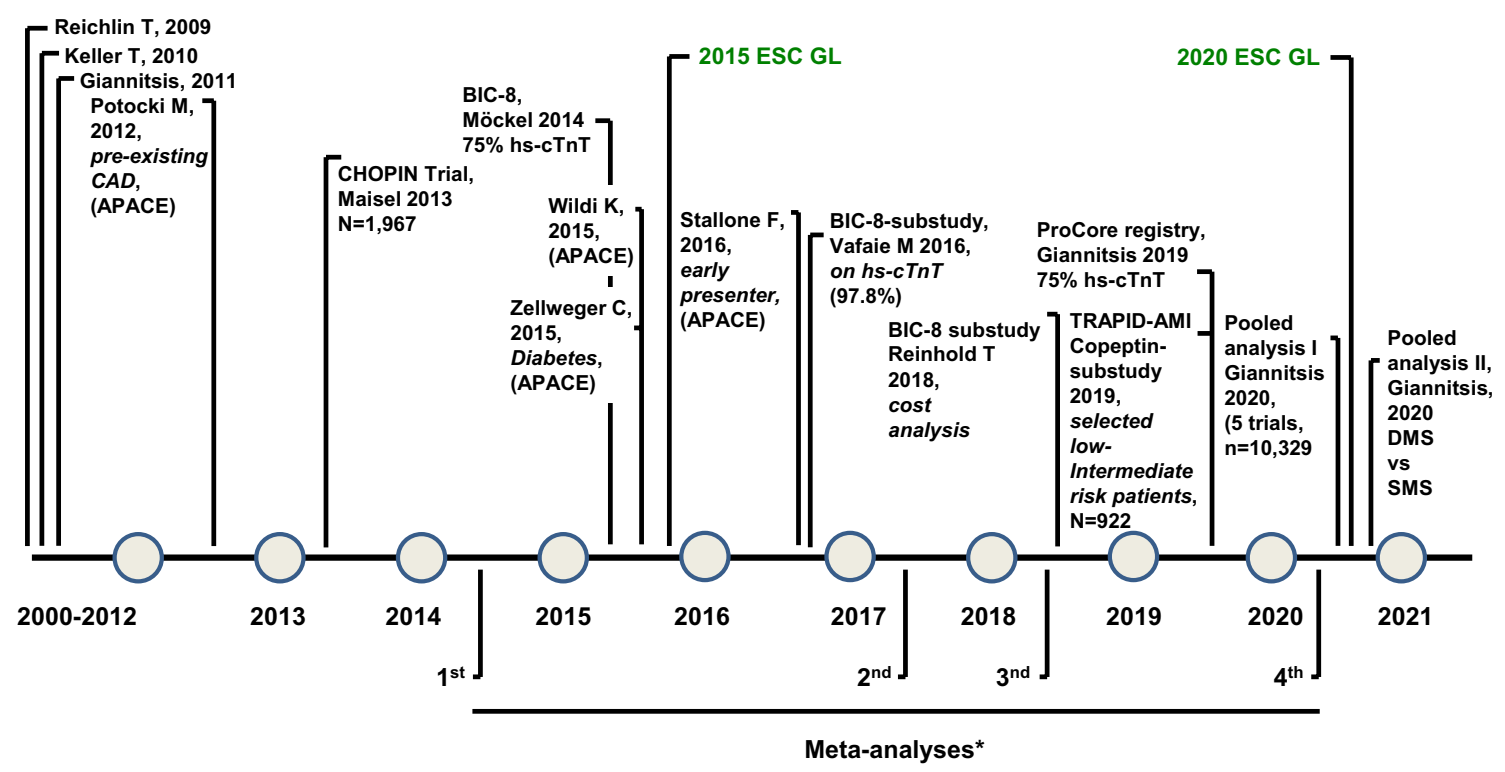

Fig. 1 Accumulating evidence supporting the usefulness and added value of Copeptin in addition to cTn or hs-cTn over time 
Table 1 Literature claiming insufficient evidence for added value of Copeptin and h-FABP in addition to hs-cTn for the initial diagnosis (Adapted from Möckel ref\#[82])

\begin{tabular}{|c|c|c|c|}
\hline Authors & Marker & Results & Data source and patients \\
\hline Boeddinghaus et al. 2017 [52] & Copeptin, hs-cTnT, hs-cTnI & $\begin{array}{l}\text { PPV (off-label for copeptin) better } \\
\text { with } 1 \mathrm{~h} \text { troponin }\end{array}$ & $\begin{array}{l}\text { Retrospective from APACE, } \\
n=1356\end{array}$ \\
\hline Hillinger et al. 2015 [53] & $\begin{array}{l}\text { Copeptin, hs-cTnT at } 0 \text { and } 1 \mathrm{~h} \\
\text { (off-label) }\end{array}$ & $\begin{array}{l}\text { NPV } 100 \% \text { in copeptin and hs-TnT } \\
\text { negatives }\end{array}$ & $\begin{array}{l}\text { Retrospective from APACE 2006- } \\
\text { 2011, highly selected, } n=941, \\
\text { explorative study }\end{array}$ \\
\hline Mueller et al. 2018 [54] & Copeptin & & Opinion paper \\
\hline Mueller-Hennessen et al. 2019 [55] & Copeptin, hs-cTnT & $\begin{array}{l}\text { NPV } 100 \% \text { in low-risk cohort } \\
\text { (label use) }\end{array}$ & TRAPID-AMI substudy, $n=922$ \\
\hline Stallone et al. 2016 [56] & Copeptin, hs-cTnT & $\begin{array}{l}\text { NPV in early presenters: } \\
\text { Copeptin + hs-TnT } 96 \% \\
\text { hs-TnT alone: } 92.9 \%\end{array}$ & $\begin{array}{l}\text { Retrospective from APACE } \\
\text { 2009-2011, } n=2183 \text { and } n=328 \\
\text { from Luzern; } n=2000 \text { analysed }\end{array}$ \\
\hline O`Donoghue et al. 2006 [57] & h-FABP & $\begin{array}{l}\text { Independent prognostic value } \\
\text { (death and MACE) }\end{array}$ & $\begin{array}{l}\text { Retrospective from OPUS-TIMI-16; } \\
n=2287\end{array}$ \\
\hline
\end{tabular}

adverse outcome event. Accordingly, it does not become evident why the previously assigned recommendation was not expended but rather downgraded. Besides, the class III recommendation is contradicted as the Guidelines itself state that Copeptin can be used in special situations (page 13, right column).

\section{Articles cited in support of an inferior performance of Copeptin in combination with hs-cTn}

In the 2020 ESC NSTE-ACS Guidelines, six references [52-57] are listed to support a class IIIB recommendation. These references are summarized in Table 1.

Most importantly, all referenced articles do not support an inferior diagnostic performance, and none of these articles indicate potential harm. In particular, the article by Boeddinghaus et al. [52] does not qualify for referencing because it focuses on the PPV of Copeptin which represents an offlabel use of Copeptin in the setting of a suspected ACS. Among the four possible combinations, only the combination of normal or undetectable Copeptin and cTn/hs-cTn concentrations serve for rule out. In addition, the instant rule-out protocol should not include patients at high risk. In addition, previous studies were confounded by questionable use of statistical methods [53, 54, 58, 59]. First, comparison of non-independent groups, e.g. the same patients assessed for the performance of the 0 -h versus $0-\mathrm{h} / 1-\mathrm{h}$ protocol, should be tested with the McNemar instead of Pearson's $\mathrm{Chi}^{2}$ test as the same population is tested repeatedly. Second, the evaluation of a rule-out test should be restricted to the assessment of sensitivities and NPVs but should not include specificities and PPV. Accordingly, C-statistics that assess the discriminatory ability of a continuous biomarker across the entire diagnostic spectrum, i.e. balance sensitivity and specificity are not appropriate.
The article by Hillinger [53] which derives data from the same APACE registry, demonstrates a NPV for Copeptin in combination with hs-cTnT of $100 \%$ and hence at least cannot support the claim of an inferior performance compared to the ESC $0 \mathrm{~h} / 1 \mathrm{~h}$ algorithm.

The third article is a current opinion paper from the ESC Study Group on Biomarkers in Cardiology of the Acute Cardiovascular Care Association [54]. This educational paper does not opt against the measurement of Copeptin in addition to cTn or hs-cTn. Literally, it is stated that the added value of Copeptin to hs-cTn is less obvious, at the time of drafting that document. It is also stated that while studies found a marginal increase of overall diagnostic accuracy as quantified by the AUC, there was a statistically significant and clinically relevant increase of the NPV from 96 to $99 \%$. The fourth article by Mueller-Hennessen et al. reports on the diagnostic and prognostic performance of Copeptin in addition to hs-cTnT in a substudy from the TRAPID-AMI trial [55]. Looking at the overall study cohort, a dual marker strategy (DMS) was associated with higher sensitivity (94.8 vs $89 \%$ ) and negative predictive value ( 98.3 vs $97.4 \%$ ) compared to the standard protocol based on the 99th percentile. After exclusion of high-risk patients as indicated by a modified HEART Score $>3$ points, sensitivity and NPV of DMS increased to $100 \%$ for both, with no death occurring at 30 days. Hence, this TRAPID substudy rather supports the usefulness of DMS but definitely does not indicate potential harm. The fifth article by Stallone et al. [56] reports on findings from the APACE registry on 2,511 patients with suspected ACS presenting early after symptom onset. Of those, only 2000 patients were analyzed. In early presenters, sensitivities impressively increased from 74.5 to $91.2 \%$ and negative predictive values from 92.9 to $96 \%$ by the additional use of Copeptin on top of hs-cTnT. Thus, this article rather supports the usefulness of Copeptin in early presenters, 
presumably by overcoming the troponin-blind interval in the early hours after onset of myocardial infarction.

Finally, the article by Donohue et al. [57] reports findings from the randomized "Orbofiban in patients with unstable coronary syndromes-thrombolysis in myocardial infarction-16 (TIMI-OPUS-16) trial on 2,287 patients. This paper that was published 2006 and thus many years before the introduction of hs-cTn, demonstrated an independent prognostic value for heart-type fatty acid binding protein (h-FABP) for prediction of death and major cardiac events but does not confer any information on the diagnostic value of h-FABP or other additional biomarkers.

\section{Articles in favor of a DMS combining Copeptin with high-sensitivity cardiac troponin}

In addition to these controversies, numerous articles that confer incremental information on the added value of Copeptin to cTn and particularly to hs-cTn are not mentioned, at all (Fig. 1). These articles include the following investigations:

The Biomarkers in Cardiology-8 (BIC-8) trial [48], an international multicenter intervention trial on 902 patients that randomized patients with suspected ACS and low-tointermediate risk to either the standard algorithm or the experimental DMS algorithm in the presence of a normal cTn/hsTn and a normal Copeptin [48]. This study demonstrated reduced length of stay in ED, higher discharge rates and importantly safety of discharge based on DMS that was as safe as discharge based on a standard diagnostic protocol. Of note, no death occurred in the experimental DMS arm at 30 days. This study was already presented during a Highlight Session at the 2014 ESC and corroborates the usefulness and safety of DMS based on a randomized trial design. In this RCT, Copeptin was combined with hs-cTn assays in about $2 / 3$ of all patients. To generalize findings to clinical routine, a multicenter prospective observational trial (proCORE) was conducted in 18 emergency departments in nine European countries enrolling 2,451 patients with suspected ACS [49]. This registry confirmed the safety of the ruleout strategy with DMS with a significantly lower all-cause mortality than standard of care pathway with serial troponin measurements. Of note, there was only one fatality case in the DMS arm who died from cancer. Therefore, it is miraculous, why the RCT [48] confirmed by a multicenter registry was not considered for evidence at all. In addition, a health economic substudy [50] from the BIC-8 RCT demonstrated cost effectiveness using DMS versus standard diagnostic strategy in patients presenting with suspected ACS. Finally, a pooled analysis [51] using data on patient level was used aggregating data from 10,329 patients with suspected ACS who had received a rule out of MI using DMS or a standard troponin-based strategy. A sub-analysis of 3487 patients evaluating the hs-TropT from Roche showed a higher applicability with the DMS to rule-out patients when compared to a single marker strategy with hs-cTnT for instant rule out at admission. All four important publications [48-51] were not appropriately addressed in the 2020 ESC Guidelines. Not referring to important evidence yields an unbalanced recommendation.

\section{Overemphasis on hs-cTn assays despite low global implementation of hs-cTn and fast protocols}

The 2020 ESC guidelines continue to recommend the routine use of Copeptin as an additional biomarker for the early rule out of MI only in "the increasingly uncommon setting where hs-cTn assays are not available". However, such a recommendation has no practical consequence in the light of the slow rate of global adoption of hs-cTn assays and fast protocols [14].

\section{CK-MB for the diagnosis of a re-infarction, and myosin-binding protein $C$ for the early rule out of NSTEMI}

When hs-cTn assays are not available, the ESC guideline proposes as alternative biomarkers CK-MB for the diagnosis of a re-infarction, and Copeptin or myosin-binding protein $\mathrm{C}$ for the early rule out of NSTEMI. These proposals merit some comments.

CK-MB for re-infarction diagnosis A re-infarction is defined as any acute myocardial infarction (AMI) occurring within 28 days of an incident or recurrent MI [60]. Thus, based on the release pattern of $\mathrm{cTn}$ and $\mathrm{CK}-\mathrm{MB}$, any MI occurring after 7-10 days of a previous MI will be detected more sensitively and specifically by any cTn method than by CK-MB.

The ESC Guidelines [1] refers to the use of CK-MB for early recognition of an MI occurring, supposedly, during the time interval in which cTn is still elevated owing to the first MI [1]. After any AMI, CK-MB values decrease to normal in 48-72 h, whereas cTn can remain elevated up to 7-10 days after the AMI. However, the guidelines do not take into account that CK-MB can be released by skeletal muscle in MI patients by several causes leading to loss of diagnostic specificity and that any it does not exist an unanimous value of the percent or absolute increase/fall that will define a significant CK-MB elevation after a previous MI. Of note, regardless the limited potential use of CK-MB as alternative for re-infarction the guidelines did not distinguish between CK-MB measured as catalytic activity or mass concentration. In addition, even when using contemporary methods for its measurement, cTn can detect re-infarctions occurring 
in the following 48-96 $\mathrm{h}$ after a previous MI using serial measurements [61].

Very recently, the ESC Study Group on Cardiac Biomarkers of the Association for Acute Cardiovascular Care published a current opinion article summarizing the reasons why CK-MB is no longer needed and suggests to eliminate CK-MB from the menu of biomarkers available for use in the evaluation of patients cardiovascular disease [62].

\section{Cardiac myosin-binding protein $\mathrm{C}$ for earlier NSTEMI rule} out Cardiac myosin-binding protein $\mathrm{C}$ is a specific cardiac isoform (C-protein, MYBPC3, cMyBP-C, cMyC) which myocardial abundance is at least two times that of $\mathrm{cTn}$. After an AMI, septal hypertrophy ablation or coronary artery bypass surgery, $\mathrm{cMyC}$ concentrations increase more rapidly and higher than those of cTn [63]. When measured with a so-called high-sensitivity immunoassay, its sensitivity and specificity for AMI diagnosis were comparable to that of hs-cTn [64], and the best cMyC diagnostic performance was observed in patients who presented very early after symptoms $(<3 \mathrm{~h})$ [65]. Unfortunately, the methods available for $\mathrm{cMyC}$ measurement are only partly automatable and require several hours to the result and this fact precludes its use for the Guidelines proposed purpose.
The second paper by Balmelli et al. [67] examined and compared the diagnostic and prognostic performance of selected cardiac biomarkers in 420 women and 827 men with suspected ACS recruited in the APACE study. Regarding the prognostic performance of selected biomarkers, the combination of cTnT and Copeptin outperformed cTnT alone, both in women and men. This study supports the additional use of Copeptin added to cTn but cannot be used to recommend against the use of Copeptin. The third paper based on the "Copeptin Helps in the early detection Of Patients with acute myocardial Infarction" (CHOPIN) trial [68] investigated the diagnostic performance of Copeptin added to conventional cTn in suspected ACS presenting to an ED within $6 \mathrm{~h}$ of pain onset. A total of 1,967 patients with chest pain were enrolled at 16-sites study. The primary endpoint was diagnosis of AMI. The AUC of troponin alone in the first blood sample taken in the ED was 0.86 , and increased to 0.97 by adding Copeptin. Using this double marker approach, a negative troponin and Copeptin $<14 \mathrm{pmol} / \mathrm{l}$ at presentation allowed AMI to be ruled out, with an NPV $>99 \%$ [68]. A second important result of the CHOPIN study relates to the prognostic role of Copeptin for outcome prediction at 30 days $(n=13$ deaths; survival rate $99.3 \%$ ), Copeptin was associated with adverse outcome, with a Chi-square test of 29.2 and a c-index of 0.872 , and

\footnotetext{
4. The ESC NSTE-ACS Guidelines recommend against the measurement of additional biomarkers such as mid-regional pro-A-type natriuretic peptide, high-sensitivity C-reactive protein, mid-regional pro-adrenomedullin, GDF-15, Copeptin, and h-FABP for routine risk or prognosis assessment.
}

The recommendation against the routine use of additional biomarkers is based on three citations that exclusively refer to Copeptin but not to the other listed biomarkers [48, 66, 67].

The first citation refers to the Biomarkers-in-Cardiology-8 (BIC-8) trial [48], a randomized interventional trial that randomly assigned patients to either standard of care or to the experimental Copeptin arm where patients with negative troponin and Copeptin values at admission were eligible for discharge after final clinical assessment. Among the 902 low- to intermediate-risk patients, early discharge after clinical assessment in the Copeptin and Troponin negative arm was as safe as the standard diagnostic algorithm based on serial cTn or hs-cTn measurements with the 99th percentile as diagnostic threshold [48]. The testing of Copeptin is complementary to cTn and as such this study rather supports the additional measurement of Copeptin but definitely does not imply harm by a dual biomarker strategy. In a secondary analysis, Copeptin shows significant and independent prognostic values over hs-cTnT [66].
cTnI had a Chi-square value of 13.7 and a c-index of 0.828 . Both markers were independent of each other and combining them provided significant added value ( $p=0.01$ for added value of cTnI, $p<0.0001$ for added value of Copeptin). The incremental value was visible until the end of follow-up at 180 days. Hence, the findings from the CHOPIN trial [68] corroborate the clinical usefulness of a negative Copeptin in combination with a negative cTn but more importantly demonstrate added and independent prognostic value for prediction of outcomes within 180 days after NSTE-ACS. Additional evidence from observational trials [69-72] and a meta-analysis [73] have accumulated substantial evidence for a prognostic role of Copeptin when used together with a hs-cTn. Von Haehling [71] reported data from 2,700 patients with symptomatic coronary artery disease (CAD), who either presented with suspected ACS to the ED, or for elective coronary angiography. The predictive performance of Copeptin was independent of any other clinical variables or cardiovascular risk factors, and superior to that of troponin I or other cardiac biomarkers $(p<0.0001)$. Zellweger 
et al. [74] evaluated 379 patients with diabetes mellitus in a cohort of 1,991 patients presenting with suspected NSTEACS from the APACE registry. In multivariate Cox analysis, Copeptin, and hs-TnT were strong and independent predictors of 24-month mortality. Using the dual marker strategy (Copeptin and troponin) identified two groups of high-risk patients where $22.5 \%$ of the group with hs-cTnT and Copeptin above the cutoff died. The authors conclude that while Copeptin only slightly improves the early diagnosis of AMI provided by hs-cTnT, both markers (Copeptin and troponin) predict long-term mortality accurately and independently of each other. Potocki et al. [72] reported on 1,170 consecutive patients presenting with suspected AMI and pre-existing CAD. Copeptin used at a cutoff $<9 \mathrm{pmol} / \mathrm{L}$ was a strong and independent predictor of 1-year mortality, even after inclusion of hs-cTn into the Cox regression model with a HR 4.63 (1.83-11.71). Irrespective of hs-cTn or cTn levels, patients with low levels of Copeptin had an excellent prognosis compared with patients with raised levels of both Copeptin and
cTn (360-day mortality $2.8-3.6 \%$ vs $23.1-33.8 \%, p<0.001$ ). Morawiec et al. [70] reported on 154 patients showing that the highest event-free survival at 30 days was achieved in patients stratified with an algorithm that combines hsTnT, a modified HEART Score (mHS) $\leq 3$, and Copeptin, with $100 \%$ (95\% CI 75.3-100) NPV and 100\% (95\% CI 96.6-100) sensitivity. Another article by Reiter et al. [75] based on patients recruited in the APACE study reported on the diagnostic and prognostic value of biomarkers added to hs-cTn. In 1,074 patients evaluated for suspected NSTEACS, heart-type fatty acid binding protein (h-FABP) and Copeptin did not improve the diagnosis of patients but were found to add independent incremental prognostic information beyond hs-TnT. When adjusted to hs-cTnT levels, age, sex and cardiovascular risk factors, h-FABP had additional predictive value regarding mortality (HR 1.023 (95\% CI 1.011 to 1.036$), p<0.001)$ beyond hs-cTnT $(p>0.05)$. This was also the case for Copeptin after adjustment (adj. HR 1.004 (95\% CI 1.002 to 1.006$), p<0.001$ ).

5. Preferable use of BNP or NT-pro BNP for prognostic assessment in NSTE-ACS

The 2020 ESC Guidelines [1] recommend that concentrations of BNP or NT-pro BNP should be used to gain prognostic information. The class IIa recommendation in favor of BNP or NT-pro BNP regarding prognostic information is based on three articles [76-78], a publication from the Study Group on Biomarkers in Cardiology [76] and two historic original publications dating back to 2001 [77] and 2003 [78], investigating the prognostic value of BNP or NT-pro $\mathrm{BNP}$ added to conventional $\mathrm{cTn}$. More recent findings on the prognostic value of natriuretic peptides including BNP,
NT-pro BNP, pro ANP or MR-pro ADM when added to an hs-cTn assay were not mentioned, at all. In the MERLINTIMI 36 trial [69] on 4,432 patients with NSTE-ACS who were randomized to treatment with ranolazine or placebo, MR-proADM and MR-proANP and Copeptin were found to add complementary prognostic information for $\mathrm{CV}$ death and HF in patients with NSTE-ACS performing as well as or better than BNP, cTnI, ST2, PAPP-A, and MPO (each $p \leq 0.01$ ).

6. Additional biomarkers do not add but marginal information in risk assessment to the GRACE score or BNP/NT-pro BNP.

Recommendation of 2020 ESC Guidelines [1] on the marginal prognostic benefit of natriuretic peptides when added on top of the GRACE Score. The statement that additional biomarkers do not add significant but only marginal information for risk assessment to the GRACE risk score is not supported by existing evidence. Von Haehling [71] studied the role of Copeptin relative to the conventional GRACE Score (version 1) in a subgroup of 1,385 patients from a catheterization-laboratory cohort comprising 2,700 patients with symptomatic CAD. They reported a significant added value when Copeptin was added to the GRACE score compared to the GRACE score alone (AUC 0.718 vs $0.618, p<0.00001$ ). The AUC was higher than the model combining hs-cTnI Siemens ultra with the GRACE score (AUC 0.718 vs 0.623 ).

In an early investigation by Widera et al. in 1,122 patients with NSTE-ACS [79], that used a rigorous derivation/validation study design, GDF-15 was found to considerably add discriminatory information to the GRACE score (Version 1) with an increase in the AUC from 0.79 to 0.85 for the combined primary endpoint of death or non-fatal MI (the endpoint for which the score was developed). Adjustment of GRACE-predicted risks by GDF-15 led to a substantial 
proportion of patients appropriately being reclassified into higher or lower risks (a net $31 \%$ of the patients without events were reclassified into lower risk and a net $27 \%$ of patients with events were reclassified into higher risk), an effect size that can be classified as strong. In another study comparing the prognostic performance of 9 biomarkers and the GRACE score (Version 1) in 1,146 patients with NSTEACS [80], GDF-15 (AUC, 0.771), the GRACE score (AUC, 0.749), and NT-proBNP (AUC, 0.745) displayed the greatest discriminatory strength, and GDF-15 was the single biomarker that added most to the GRACE score. A recent study in 4,330 patients with NSTE-ACS enrolled in the MERLINTIMI 36 trial [81] using the new clinically available GDF-15 assay supports the conclusion that GDF-15 independently predicts risk in NSTE-ACS. It should be emphasized that the added value of biomarkers (including BNP/NT-pro BNP) to the new GRACE score (Version 2) has not been studied with the same methodological rigor. The conclusion that "additional biomarkers do not add but marginal information in risk assessment to the GRACE score or BNP/NT-pro BNP", therefore, seems unjustified.

Funding Open Access funding enabled and organized by Projekt DEAL.

\section{Compliance with ethical standards}

Conflict of interest EG declares honoraria for lectures from Daiichi Sankyo, Astra Zeneca, Roche Diagnostics, Boehringer Ingelheim, Bayer Vital, and BRAHMS GmbH. He receives research funding from Daiichi Sankyo and Roche Diagnostics. He consults Roche Diagnostics, Astra Zeneca, Bayer Vital, Indorsia, Radiometer, BRAHMS $\mathrm{GmbH}$, Hoffmann-La Roche, and Boehringer Ingelheim. SvH has been a paid consultant for and/or received honoraria payments from Bayer, Boehringer Ingelheim, BRAHMS, Chugai, Grünenthal, Helsinn, Hexal, Novartis, Pharmacosmos, Respicardia, Roche, Servier, Sorin, and Vifor; owns shares in Actimed. SvH reports research support from Amgen, Boehringer Ingelheim, IMI and the German Center for Cardiovascular Research (DZHK). HAK received speaker honoraria from Bayer Vital, Astra Zeneca, Novo Nordisk, Roche Diagnostics, Boehringer Ingelheim. He consults for Bayer Vital, Astra Zeneca and Boehringer Ingelheim. CWH has received speaker honoraria from AstraZeneca, Bayer, Boehringer Ingelheim, Daiichi Sankyo, Roche, Pfizer and consults for AstraZeneca, Daiichi Sankyo, Brahms GmbH. KH declares lecture and/or consulting fees from AMGEN, AstraZeneca, Bayer, Boehringer Ingelheim, Brahms/Thermofisher, Daiichi Sankyo, Eli Lilly, Ferrer, Idorsia, Novartis, Pfizer, Portola, Roche Diagnostics, Sanofi Aventis, The Medicines Company and Vifor Pharma. MM received honoraria for lectures from Roche Diagnostics, AstraZeneca, Bayer Vital, Daiichi Sankyo, Boehringer Ingelheim and BRAHMS Thermo Fisher Scientific. He serves as a consultant for BRAHMS Thermo Fisher Scientific and Bayer, and has received research funding from BRAHMS Thermo Fisher Scientific, Roche Diagnostics and Radiometer. KCW declares honoraria for lectures from Roche Diagnostics. $\mathrm{He}$ received research funding from Roche Diagnostics and Boehringer Ingelheim. He consults Boehringer Ingelheim. JWCT reports modest honoraria from Astra Zeneca, Bayer, Amgen, Medtronic, Abbott Vascular, Biosensors, Orbus Neich, Boehringer Ingelheim, Pfizer; research grants from Medtronic, Abbott Diagnostics and Beckmann. Educational grants Abbott Vascular, Amgen, Astra Zeneca, Bayer, Bi- otronik, Biosensors, Philips, Medtronic, Ostuka, Impulse Dyanamics and Roche Diagnostics. Consulting: Elixir Medical. KI declares honoraria for lectures from Otsuka and Bayel. He received research funding from Roche Diagnostics, SB Bio science, Fujirebio, Kanto Chemical, Sysmecs, Bayel, Otsuka. JMC reports research support from Roche Diagnostics, Siemens, Abbott, Beckman, and consulting for Beckman, Roche Diagnostics and Siemens. NF received lecture honoraria from AstraZeneca, BayerVital, Boehringer Ingelheim and Novartis.

Open Access This article is licensed under a Creative Commons Attribution 4.0 International License, which permits use, sharing, adaptation, distribution and reproduction in any medium or format, as long as you give appropriate credit to the original author(s) and the source, provide a link to the Creative Commons licence, and indicate if changes were made. The images or other third party material in this article are included in the article's Creative Commons licence, unless indicated otherwise in a credit line to the material. If material is not included in the article's Creative Commons licence and your intended use is not permitted by statutory regulation or exceeds the permitted use, you will need to obtain permission directly from the copyright holder. To view a copy of this licence, visit http://creativecommons.org/licenses/by/4.0/.

\section{References}

1. Collet JP, Thiele H, Barbato E, Barthélémy O, Bauersachs J, Bhatt DL, Dendale P, Dorobantu M, Edvardsen T, Folliguet T, Gale CP, Gilard M, Jobs A, Jüni P, Lambrinou E, Lewis BS, Mehilli J, Meliga E, Merkely B, Mueller C, Roffi M, Rutten FH, Sibbing D, Siontis GCM, ESC Scientific Document Group (2020) 2020 ESC Guidelines for the management of acute coronary syndromes in patients presenting without persistent ST-segment elevation. Eur Heart J. https://doi.org/10.1093/eurheartj/ehaa575 (Epub ahead of print. PMID: 32860058)

2. Roffi M, Patrono C, Collet JP, Mueller C, Valgimigli M, Andreotti F, Bax JJ, Borger MA, Brotons C, Chew DP, Gencer B, Hasenfuss G, Kjeldsen K, Lancellotti P, Landmesser U, Mehilli J, Mukherjee D, Storey RF, Windecker S (2016) 2015 ESC Guidelines for the management of acute coronary syndromes in patients presenting without persistent ST-segment elevation: Task Force for the Management of Acute Coronary Syndromes in Patients Presenting without Persistent ST-Segment Elevation of the European Society of Cardiology (ESC). Eur Heart J. 37:267-315. https:// doi.org/10.1093/eurheartj/ehv320 (Epub 2015 Aug 29 PMID: 26320110)

3. Rui P, Kang K, Ashman JJ. National Hospital ambulatory medical care survey: 2016 emergency department summary tables. 2016. https://www.cdc.gov/nchs/data/nhamcs/web_tables/2016_ed_ web_tables.pdf

4. Goodacre S, Thokala P, Carroll C et al (2013) Systematic review, meta-analysis and economic modelling of diagnostic strategies for suspected acute coronary syndrome. Health Technol Assess $17: 1-188$

5. Stoyanov KM, Biener M, Hund H, Mueller-Hennessen M, Vafaie M, Katus HA, Giannitsis E (2020) Effects of crowding in the emergency department on the diagnosis and management of suspected acute coronary syndrome using rapid algorithms: an observational study. BMJ Open 10:e041757. https://doi.org/10.1136/ bmjopen-2020-041757.PMID:33033102;PMCID:PMC7545662

6. Hamm CW, Bassand JP, Agewall S, Bax J, Boersma E, Bueno H, Caso P, Dudek D, Gielen S, Huber K, Ohman M, Petrie MC, Sonntag F, Uva MS, Storey RF, Wijns W, Zahger D, Committee ESC, for Practice Guidelines, (2011) ESC Guidelines for the management of acute coronary syndromes in patients presenting 
without persistent ST-segment elevation: The Task Force for the management of acute coronary syndromes (ACS) in patients presenting without persistent ST-segment elevation of the European Society of Cardiology (ESC). Eur Heart J 32:2999-3054. https ://doi.org/10.1093/eurheartj/ehr236 (Epub 2011 Aug 26 PMID: 21873419)

7. Chew DP, Lambrakis K, Blyth A, Seshadri A, Edmonds MJR, Briffa T, Cullen LA, Quinn S, Karnon J, Chuang A, Nelson AJ, Wright D, Horsfall M, Morton E, French JK, Papendick CA (2019) Randomized trial of a 1-hour troponin t protocol in suspected acute coronary syndromes: the rapid assessment of possible acute coronary syndrome in the emergency department with high-sensitivity troponin T study (RAPID-TnT). Circulation 140:1543-1556. https://doi.org/10.1161/CIRCULATIO NAHA.119.042891 (Epub 2019 Sep 3 PMID: 31478763)

8. Stoyanov KM, Hund H, Biener M, Gandowitz J, Riedle C, Löhr J, Mueller-Hennessen M, Vafaie M, Katus HA, Giannitsis E (2020) RAPID-CPU: a prospective study on implementation of the ESC 0/1-hour algorithm and safety of discharge after rule-out of myocardial infarction. Eur Heart J Acute Cardiovasc Care 9:39-51. https://doi.org/10.1177/2048872619861911 (Epub 2019 Jul)

9. Twerenbold R, Costabel JP, Nestelberger T, Campos R, Wussler D, Arbucci R, Cortes M, Boeddinghaus J, Baumgartner B, Nickel $\mathrm{CH}$, Bingisser R, Badertscher P, Puelacher C, du Fay de Lavallaz J, Wildi K, Rubini Giménez M, Walter J, Meier M, Hafner B, Lopez Ayala P, Lohrmann J, Troester V, Koechlin L, Zimmermann T, Gualandro DM, Reichlin T, Lambardi F, Resi S, Alves de Lima A, Trivi M, Mueller C (2019) Outcome of applying the ESC 0/1-hour algorithm in patients with suspected myocardial infarction. J Am Coll Cardiol. 74:483-494. https://doi.org/10.1016/j. jacc.2019.05.046 (PMID: 31345421)

10. Chiang $\mathrm{CH}$, Chiang $\mathrm{CH}$, Lee GH, Gi WT, Wu YK, Huang SS, Yeo YH, Giannitsis E, Lee CC (2020) Safety and efficacy of the European Society of Cardiology 0/1-hour algorithm for diagnosis of myocardial infarction: systematic review and meta-analysis. Heart 106:985-991. https://doi.org/10.1136/heartjnl-2019-31634 3 (Epub 2020 Apr 3 PMID: 32245882)

11. Twerenbold R, Jaeger C, Rubini Gimenez M et al (2016) Impact of high-sensitivity cardiac troponin on use of coronary angiography, cardiac stress testing, and time to discharge in suspected acute myocardial infarction. Eur Heart J 37:3324-3332. https:// doi.org/10.1093/eurheartj/ehw232

12. Ambavane A, Lindahl B, Giannitsis E, Roiz J, Mendivil J, Frankenstein L, Body R, Christ M, Bingisser R, Alquezar A, Mueller C, TRAPID-AMI investigators (2017) Economic evaluation of the one-hour rule-out and rule-in algorithm for acute myocardial infarction using the high-sensitivity cardiac troponin $\mathrm{T}$ assay in the emergency department. PLoS ONE 12:e0187662. https://doi.org/10.1371/journal.pone.0187662. (Erratum.In:PL oSOne.2018Jan11;13(1):e0191348.PMID:29121105;PMCID: PMC5679593)

13. Crea F, Jaffe AS, Collinson PO, Hamm CW, Lindahl B, Mills NL, Thygesen K, Mueller C, Patrono C, Roffi M, 2015 ESC NSTEACS Guidelines Task Force (2016) Should the 1h algorithm for rule in and rule out of acute myocardial infarction be used universally? Eur Heart J 37:3316-3323. https://doi.org/10.1093/eurhe artj/ehw282 (PMID: 28007934)

14. Anand A, Shah ASV, Beshiri A, Jaffe AS, Mills NL (2019) Global adoption of high-sensitivity cardiac troponins and the universal definition of myocardial infarction. Clin Chem 65:484-489. https ://doi.org/10.1373/clinchem.2018.298059 (Epub 2019 Jan 9 PMID: 30626631)

15. Pickering JW, Than MP, Cullen L et al (2017) Rapid rule-out of acute myocardial infarction with a single high-sensitivity cardiac troponin $\mathrm{T}$ measurement below the limit of detection: a collaborative meta-analysis. Ann Intern Med 166:715-724. https ://doi.org/10.7326/M16-2562

16. Vafaie M, Katus HA (2018) Accuracy of 0/1-hour algorithm for diagnosis of MI in the elderly: mono-dimensional optimization of troponin cut-offs for individual confounders or precision medicine? Eur Heart J 39:3795-3797. https://doi.org/10.1093/eurhe artj/ehy526 (PMID: 30188981)

17. Cain PA, Ahl R, Hedstrom E, Ugander M, Allansdotter-Johnsson A, Friberg P, Arheden H (2009) Age and gender specific normal values of left ventricular mass, volume and function for gradient echo magnetic resonance imaging: a cross sectional study. BMC Med Imaging 9:2. https://doi.org/10.1186/1471-2342-9-2. (PMI D:19159437;PMCID:PMC2657902)

18. Apple FS, Ler R, Murakami MM (2012) Determination of 19 cardiac troponin I and T assay 99th percentile values from a common presumably healthy population. Clin Chem 58:1574-1581. https://doi.org/10.1373/clinchem.2012.192716

19. Giannitsis E, Kurz K, Hallermayer K, Jarausch J, Jaffe AS, Katus HA (2010) Analytical validation of a high-sensitivity cardiac troponin T assay. Clin Chem 56:254-261. https://doi.org/10.1373/ clinchem.2009.132654 (Epub 2009 Dec 3 PMID: 19959623)

20. Giannitsis E, Katus HA (2012) Pros and cons of high-sensitivity assays for cardiac troponin. Nat Rev Cardiol 9:616-618. https ://doi.org/10.1038/nrcardio.2012.142 (Epub 2012 Oct 2 PMID: 23026865)

21. Thygesen K, Alpert J, Jaffe AS, Chaitman BR, Bax JJ, Morrow DA, White HD, the Executive Group on behalf of the Joint European Society of Cardiology (ESC)/American College of Cardiology (ACC)/American Heart Association (AHA)/World Heart Federation (2018) Fourth universal definition of myocardial infarction. Eur Heart J 138:e618-e651

22. Rubini Giménez M, Twerenbold R, Boeddinghaus J, Nestelberger T, Puelacher C, Hillinger P, Wildi K, Jaeger C, Grimm K, Heitzelmann KF, Sabti Z, Badertscher P, Cupa J, Honegger U, Schaerli N, Kozhuharov N, du Fay de Lavallaz J, Lopez B, Salgado E, Miró Ò, Martín-Sánchez FJ, Adrada ER, Morawiec B, Parenica J, Ganovska E, Neugebauer C, Rentsch K, Lohrmann J, Osswald S, Reichlin T, Mueller C (2016) Clinical effect of sex-specific cutoff values of high-sensitivity cardiac troponin $\mathrm{T}$ in suspected myocardial infarction. JAMA Cardiol. 1:912-920. https://doi. org/10.1001/jamacardio.2016.2882

23. Shah AS, Griffiths M, Lee KK, McAllister DA, Hunter AL, Ferry AV et al (2015) High sensitivity cardiac troponin and the underdiagnosis of myocardial infarction in women: prospective cohort study. BMJ 350:g7873

24. Collinson PO, Saenger AK, Apple FS (2019) High sensitivity, contemporary and point-of-care cardiac troponin assays: educational aids developed by the IFCC committee on clinical application of cardiac bio-markers. Clin Chem Lab Med 57:623-632. https://doi.org/10.1515/cclm-2018-1211

25. Christenson RH, Mullins K, Duh SH (2018) Validation of highsensitivity performance for a United States Food and Drug Administration cleared cardiac troponin I assay. Clin Biochem $56: 4-10$

26. https://www.accessdata.fda.gov/cdrh_docs/reviews/K100130.pdf. Accessed 17 Nov 2020

27. Sörensen NA, Neumann JT, Ojeda F, Giannitsis E, Spanuth E, Blankenberg S, Westermann D, Zeller T (2019) Diagnostic evaluation of a high-sensitivity troponin I point-of-care assay. Clin Chem 65:1592-1601. https://doi.org/10.1373/clinc hem.2019.307405 (Epub 2019 Nov 7 PMID: 31699700)

28. Venge P, van Lippen L, Blaschke S, Christ M, Geier F, Giannitsis E, Hagström E, Hausfater P, Khellaf M, Mair J, Pariente D, Scharnhorst V, Semjonow V (2017) Equal clinical performance of a novel point-of-care cardiac troponin I (cTnI) assay with a commonly used high-sensitivity cTnI assay. Clin Chim Acta 
469:119-125. https://doi.org/10.1016/j.cca.2017.03.023 (Epub 2017 Mar 25 PMID: 28347675)

29. Boeddinghaus J, Nestelberger T, Koechlin L, Wussler D, LopezAyala P, Walter JE, Troester V, Ratmann PD, Seidel F, Zimmermann T, Badertscher P, Wildi K, Rubini Giménez M, Potlukova E, Strebel I, Freese M, Miró Ò, Martin-Sanchez FJ, Kawecki D, Keller DI, Gualandro DM, Christ M, Twerenbold R, Mueller C, Investigators APACE (2020) Early diagnosis of myocardial infarction with point-of-care high-sensitivity cardiac troponin I. J Am Coll Cardiol 75:1111-1124. https://doi.org/10.1016/j.jacc.2019.12.065

30. Pickering JW, Young JM, George PM, Watson AS, Aldous SJ, Troughton RW, Pemberton CJ, Richards AM, Cullen LA, Than MP (2018) Validity of a novel point-of-care troponin assay for single-test rule-out of acute myocardial infarction. JAMA Cardiol 3:1108-1112. https://doi.org/10.1001/jamacardio.2018.3368. PMID:30347004;PMCID:PMC6583693

31. Apple FS (2009) A new season for cardiac troponin assays: it's time to keep a scorecard. Clin Chem 55:1303-1306. https://doi. org/10.1373/clinchem.2009.128363 (Epub 2009 May 28 PMID: 19478023)

32. Wu AHB, Christenson RH, Greene DN et al (2018) Clinical laboratory practice recommendations for the use of cardiac troponin in acute coronary syndrome: expert opinion from the academy of the american association for clinical chemistry and the task force on clinical applications of cardiac bio-markers of the international federation of clinical chemistry and laboratory medicine. Clin Chem 64:645-655. https://doi.org/10.1373/clinchem.2017.277186

33. Neumann JT, Twerenbold R, Ojeda F, Sörensen NA, Chapman AR, Shah ASV, Anand A, Boeddinghaus J, Nestelberger T, Badertscher P, Mokhtari A, Pickering JW, Troughton RW, Greenslade J, Parsonage W, Mueller-Hennessen M, Gori T, Jernberg T, Morris N, Liebetrau C, Hamm C, Katus HA, Münzel T, Landmesser U, Salomaa V, Iacoviello L, Ferrario MM, Giampaoli S, Kee F, Thorand B, Peters A, Borchini R, Jørgensen T, Söderberg S, Sans S, Tunstall-Pedoe H, Kuulasmaa K, Renné T, Lackner KJ, Worster A, Body R, Ekelund U, Kavsak PA, Keller T, Lindahl B, Wild P, Giannitsis E, Than M, Cullen LA, Mills NL, Mueller C, Zeller T, Westermann D, Blankenberg S (2019) Application of highsensitivity troponin in suspected myocardial infarction. N Engl J Med 380:2529-2540. https://doi.org/10.1056/NEJMoa1803377 (PMID: 31242362)

34. Boeddinghaus $\mathrm{J}$, Twerenbold $\mathrm{R}$, Nestelberger $\mathrm{T}$, Badertscher P, Wildi K, Puelacher C, du Fay de Lavallaz J, Keser E, Rubini Giménez M, Wussler D, Kozhuharov N, Rentsch K, Miró Ò, Martin-Sanchez FJ, Morawiec B, Stefanelli S, Geigy N, Keller DI, Reichlin T, Mueller C, Investigators APACE (2018) Clinical validation of a novel high-sensitivity cardiac troponin I assay for early diagnosis of acute myocardial infarction. Clin Chem 64:1347-1360. https://doi.org/10.1373/clinchem.2018.286906 (Epub 2018 Jun 25 PMID: 29941469)

35. Reichlin T, Irfan A, Twerenbold R, Reiter M, Hochholzer W, Burkhalter H, Bassetti S, Steuer S, Winkler K, Peter F, Meissner J, Haaf P, Potocki M, Drexler B, Osswald S, Mueller C (2011) Utility of absolute and relative changes in cardiac troponin concentrations in the early diagnosis of acute myocardial infarction. Circulation 124:136-145. https://doi.org/10.1161/CIRCULATIO NAHA.111.023937 (Epub 2011 Jun 27 PMID: 21709058)

36. Boeddinghaus J, Reichlin T, Cullen L, Greenslade JH, Parsonage WA, Hammett C, Pickering JW, Hawkins T, Aldous S, Twerenbold R, Wildi K, Nestelberger T, Grimm K, Rubini-Gimenez M, Puelacher C, Kern V, Rentsch K, Than M, Mueller C (2016) Two-hour algorithm for triage toward rule-out and rule-in of acute myocardial infarction by use of high-sensitivity cardiac troponin I. Clin Chem 62:494-504. https://doi.org/10.1373/clinc hem.2015.249508 (Epub 2016 Jan 21 PMID: 26797687)
37. Nestelberger T, Boeddinghaus J, Greenslade J, Parsonage WA, Than M, Wussler D, Lopez-Ayala P, Zimmermann T, Meier M, Troester V, Badertscher P, Koechlin L, Wildi K, Anwar M, Freese M, Keller DI, Reichlin T, Twerenbold R, Cullen L, Mueller C (2019) Two-hour algorithm for rapid triage of suspected acute myocardial infarction using a high-sensitivity cardiac troponin I assay. Clin Chem. 65:1437-1447

38. Eggers KM, Jernberg T, Ljung L, Lindahl B (2018) High-sensitivity cardiac troponin-based strategies for the assessment of chest pain patients-a review of validation and clinical implementation studies. Clin Chem 64:1572-1585. https://doi.org/10.1373/clinc hem.2018.287342 (Epub 2018 Jun 25 PMID: 29941466)

39. Than M, Cullen L, Aldous S, Parsonage WA, Reid CM, Greenslade J et al (2012) 2-Hour accelerated diagnostic protocol to assess patients with chest pain symptoms using contemporary troponins as the only biomarker: the ADAPT trial. J Am Coll Cardiol 59:2091-2098

40. Than M, Flaws D, Sanders S, Doust J, Glasziou P, Kline J et al (2014) Development and validation of the emergency department assessment of chest pain score and $2 \mathrm{~h}$ accelerated diagnostic protocol. Emerg Med Australas 26:34-44

41. Than MP, Pickering JW, Aldous SJ, Cullen L, Frampton CM, Peacock WF et al (2016) Effectiveness of EDACS versus ADAPT accelerated diagnostic pathways for chest pain: a pragmatic randomized controlled trial embedded within practice. Ann Emerg Med 68:93-102

42. Than M, Aldous S, Lord SJ, Goodacre S, Frampton CM, Troughton R, George P, Florkowski CM, Ardagh M, Smyth D, Jardine DL, Peacock WF, Young J, Hamilton G, Deely JM, Cullen L, Richards AM (2014) A 2-hour diagnostic protocol for possible cardiac chest pain in the emergency department: a randomized clinical trial. JAMA Intern Med 174:51-58. https://doi. org/10.1001/jamainternmed.2013.11362 (PMID: 24100783)

43. Wildi K, Cullen L, Twerenbold R, Greenslade JH, Parsonage W, Boeddinghaus J, Nestelberger T, Sabti Z, Rubini-Giménez M, Puelacher C, Cupa J, Schumacher L, Badertscher P, Grimm K, Kozhuharov N, Stelzig C, Freese M, Rentsch K, Lohrmann J, Kloos W, Buser A, Reichlin T, Pickering JW, Than M, Mueller C (2017) Direct comparison of 2 rule-out strategies for acute myocardial infarction: 2 -h accelerated diagnostic protocol vs $2-\mathrm{h}$ algorithm. Clin Chem 63:1227-1236. https://doi.org/10.1373/ clinchem.2016.268359 (Epub 2017 May 17 PMID: 28515106)

44. Wildi K, Nelles B, Twerenbold R, Rubini Gimenez M, Reichlin T, Singeisen H, Druey S, Haaf P, Sabti Z, Hillinger P, Jaeger C, Campodarve I, Kreutzinger P, Puelacher C, Moreno Weidmann Z, Gugala M, Pretre G, Doerflinger S, Wagener M, Stallone F, Freese M, Stelzig C, Rentsch K, Bassetti S, Bingisser R, Osswald S, Mueller C (2016) Safety and efficacy of the $0 \mathrm{~h} / 3 \mathrm{~h}$ protocol for rapid rule out of myocardial infarction. Am Heart J 181:16-25

45. Badertscher P, Boeddinghaus J, Twerenbold R, Nestelberger T, Wildi K, Wussler D, Schwarz J, Puelacher C, Rubini G, Kozhuharov M, du Fay de Lavallaz N, Cerminara J, Potlukova SE, Rentsch E, Miro K, Lopez O, Martin-Sanchez B, Morawiec FJ, Muzyk B, Keller P, Reichlin DI, Mueller T, APACE Investigators $\mathrm{C}$ (2018) Direct comparison of the $0 / 1 \mathrm{~h}$ and $0 / 3 \mathrm{~h}$ algorithms for early rule-out of acute myocardial infarction. Circulation 137:2536-2538

46. Chapman AR, Anand A, Boeddinghaus J, Ferry AV, Sandeman D, Adamson PD, Andrews J, Tan S, Cheng SF, D'Souza M, Orme K, Strachan FE, Nestelberger T, Twerenbold R, Badertscher P, Reichlin T, Gray A, Shah ASV, Mueller C, Newby DE, Mills NL (2017) Comparison of the efficacy and safety of early rule-out pathways for acute myocardial infarction. Circulation 135:1586-1596

47. Chapman AR, Fujisawa T, Lee KK, Andrews JP, Anand A, Sandeman D, Ferry AV, Stewart S, Marshall L, Strachan FE, Gray A, Newby DE, Shah ASV, Mills NL (2019) Novel high-sensitivity 
cardiac troponin I assay in patients with suspected acute coronary syndrome. Heart 105:616-622

48. Möckel M, Searle J, Hamm C, Slagman A, Blankenberg S, Huber K, Katus H, Liebetrau C, Müller C, Muller R, Peitsmeyer P, von Recum J, Tajsic M, Vollert JO, Giannitsis E (2015) Early discharge using single cardiac troponin and copeptin testing in patients with suspected acute coronary syndrome ACS a randomized, controlled clinical process study. Eur Heart J. 36:369376. https://doi.org/10.1093/eurheartj/ehu178

49. Giannitsis E, Clifford P, Slagman A, Ruedelstein R, Liebetrau C, Hamm C, Honnart D, Huber K, Vollert JO, Simonelli C, Schröder M, Wiemer JC, Mueller-Hennessen M, Schroer H, Kastner K, Möckel M (2019) Multicentre cross-sectional observational registry to monitor the safety of early discharge after rule-out of acute myocardial infarction by copeptin and troponin: the Pro-Core registry. BMJ Open 9:e028311. https://doi.org/10.1136/bmjop en-2018-028311.PMID:31340965;PMCID:PMC6661885

50. Reinhold T, Giannitsis E, Möckel M, Frankenstein L, Vafaie M, Vollert JO, Slagman A (2018) Cost analysis of early discharge using combined copeptin/cardiac troponin testing versus serial cardiac troponin testing in patients with suspected acute coronary syndrome. PLoS ONE 13:e0202133. https://doi.org/10.1371/journ al.pone.0202133 (PMID:30138394;PMCID:PMC6107144)

51. Giannitsis E, Huber K, Hamm CW, Möckel M (2020) Instant ruleout of suspected non-ST-segment elevation myocardial infarction using high-sensitivity cardiac troponin $\mathrm{T}$ with Copeptin versus a single low high-sensitivity cardiac troponin $\mathrm{T}$ : findings from a large pooled individual data analysis on 10,329 patients. Clin Res Cardiol. https://doi.org/10.1007/s00392-020-01712-y (Epub ahead of print. PMID: 32671467)

52. Boeddinghaus J, Reichlin T, Nestelberger T, Twerenbold R, Meili Y, Wildi K, Hillinger P, Gimenez MR, Cupa J, Schumacher L, Schubera M, Badertscher P, Corbiere S, Grimm K, Puelacher C, Sabti Z, Widmer DF, Schaerli N, Kozhuharov N, Shrestha S, Burge T, Machler P, Buchi M, Rentsch K, Miro O, Lopez B, Martin-Sanchez FJ, Rodriguez-Adrada E, Morawiec B, Kawecki D, Ganovska E, Parenica J, Lohrmann J, Buser A, Keller DI, Osswald S, Mueller C (2017) Early diagnosis of acute myocardial infarction in patients with mild elevations of cardiac troponin. Clin Res Cardiol 106:457-467

53. Hillinger P, Twerenbold R, Jaeger C, Wildi K, Reichlin T, Rubini Gimenez M, Engels U, Miro O, Boeddinghaus J, Puelacher C, Nestelberger T, Rothlisberger M, Ernst S, Rentsch K, Mueller C (2015) Optimizing early rule-out strategies for acute myocardial infarction: utility of 1-hour copeptin. Clin Chem 61:1466-1474

54. Mueller C, Möckel M, Giannitsis E, Huber K, Mair J, Plebani M, Thygesen K, Jaffe AS, Lindahl B, ESC Study Group on Biomarkers in Cardiology of the Acute Cardiovascular Care Association (2018) Use of copeptin for rapid rule-out of acute myocardial infarction. Eur Heart J Acute Cardiovasc Care. 7:570-576. https ://doi.org/10.1177/2048872617710791 (Epub 2017 Jun 8 PMID: 28593800)

55. Mueller-Hennessen M, Lindahl B, Giannitsis E, Vafaie M, Biener M, Haushofer AC, Seier J, Christ M, Alquezar-Arbe A, deFilippi CR, McCord J, Body R, Panteghini M, Jernberg T, Plebani M, Verschuren F, French JK, Christenson RH, Dinkel C, Katus HA, Mueller C (2019) Combined testing of copeptin and highsensitivity cardiac troponin $\mathrm{T}$ at presentation in comparison to other algorithms for rapid rule-out of acute myocardial infarction. Int $\mathrm{J}$ Cardiol 276:261-267

56. Stallone F, Schoenenberger AW, Puelacher C, Rubini Gimenez M, Walz B, Naduvilekoot Devasia A, Bergner M, Twerenbold R, Wildi K, Reichlin T, Hillinger P, Erne P, Mueller C (2016) Incremental value of copeptin in suspected acute myocardial infarction very early after symptom onset. Eur Heart J Acute Cardiovasc Care 5:407-415
57. O'Donoghue M, de Lemos JA, Morrow DA, Murphy SA, Buros JL, Cannon CP, Sabatine MS (2006) Prognostic utility of hearttype fatty acid binding protein in patients with acute coronary syndromes. Circulation 114:550-557

58. Wildi K, Zellweger C, Twerenbold R, Jaeger C, Reichlin T, Haaf P, Faoro J, Giménez MR, Fischer A, Nelles B, Druey S, Krivoshei L, Hillinger P, Puelacher C, Herrmann T, Campodarve I, Rentsch K, Steuer S, Osswald S, Mueller C (2015) Incremental value of copeptin to highly sensitive cardiac Troponin I for rapid rule-out of myocardial infarction. Int J Cardiol 190:170-176. https://doi. org/10.1016/j.ijcard.2015.04.133 (Epub 2015 Apr 17 PMID: $\mathbf{2 5 9 1 8 0 7 3 ) ~}$

59. Wildi K, Boeddinghaus J, Nestelberger T, Twerenbold R, Badertscher P, Wussler D, Giménez MR, Puelacher C, du Fay de Lavallaz J, Dietsche S, Walter J, Kozhuharov N, Morawiec B, Miró Ò, Javier Martin-Sanchez F, Subramaniam S, Geigy N, Keller DI, Reichlin T, Mueller C (2019) Comparison of fourteen rule-out strategies for acute myocardial infarction. Int J Cardiol. 283:4147. https://doi.org/10.1016/j.ijcard.2018.11.140 (Epub 2018 Dec 3 PMID: 30545622)

60. Mendis S, Thygesen K, Kuulasmaa K, Giampaoli S, Mahönen M, Ngu Blackett K, Lisheng L, Writing group on behalf of the participating experts of the WHO consultation for revision of WHO definition of myocardial infarction (2011) World Health Organization definition of myocardial infarction: 2008-09 revision. Int J Epidemiol 40:139-146

61. Apple FS, Murakami MM (2005) Cardiac troponin and creatine kinase MB monitoring during in-hospital myocardial reinfarction. Clin Chem 51:460-463

62. Jaffe AS, Lindahl B, Giannitsis E, Mueller C, Cullen L, Hammersten O, Moeckel M, Mair J, Krychtiuk KA, Huber K, Mills NL, Thygesen K (2021) A fond farewell to CK-MB. Current opinion from the ESC group on cardiac biomarkers of the association for acute cardio vascular care. Eur Heart J. https://doi.org/10.1093/ eurheartj/ehaa1079

63. Baker JO, Tyther R, Liebetrau C, Clark J, Howarth R, Patterson T, Möllmann H, Nef H, Sicard P, Kailey B, Devaraj R, Redwood SR, Kunst G, Weber E, Marber MS (2015) Cardiac myosin-binding protein C: a potential early biomarker of myocardial injury. Basic Res Cardiol 110:23

64. Marjot J, Liebetrau C, Goodson RJ, Kaier T, Weber E, Heseltine P, Marber MS (2016) The development and application of a highsensitivity immunoassay for cardiac myosin-binding protein $\mathrm{C}$. Transl Res 170:17-25.e5

65. Kaier TE, Twerenbold R, Puelacher C, Marjot J, Imambaccus N, Boeddinghaus J, Nestelberger T, Badertscher P, Sabti Z, Giménez MR, Wildi K, Hillinger P, Grimm K, Loeffel S, Shrestha S, Widmer DF, Cupa J, Kozhuharov N, Miró Ò, Martín-Sánchez FJ, Morawiec B, Rentsch K, Lohrmann J, Kloos W, Osswald S, Reichlin T, Weber E, Marber M, Mueller C (2017) Direct comparison of cardiac myosin-binding protein $\mathrm{C}$ with cardiac troponins for the early diagnosis of acute myocardial infarction. Circulation 136:1495-1508

66. Vafaie M, Slagman A, Möckel M, Hamm C, Huber K, Müller C, Vollert JO, Blankenberg S, Katus HA, Liebetrau C, Giannitsis E, Searle J (2016) Prognostic value of undetectable hs troponin $t$ in suspected acute coronary syndrome. Am J Med 129:274-82.e2. https://doi.org/10.1016/j.amjmed.2015.10.016 (Epub 2015 Oct 30 PMID: 26524709)

67. Balmelli C, Meune C, Twerenbold R, Reichlin T, Rieder S, Drexler B, Rubini MG, Mosimann T, Reiter M, Haaf P, Mueller M, Ernst S, Ballarino P, Alafify AA, Zellweger C, Wildi K, Moehring B, Vilaplana C, Bernhard D, Merk S, Ebmeyer S, Freidank H, Osswald S, Mueller C (2013) Comparison of the performances of cardiac troponins, including sensitive assays, and copeptin in the 
diagnostic of acute myocardial infarction and long-term prognosis between women and men. Am Heart J 166:30-37

68. Maisel A, Mueller C, Neath SX, Christenson RH, Morgenthaler NG, McCord J, Nowak RM, Vilke G, Daniels LB, Hollander JE, Apple FS, Cannon C, Nagurney JT, Schreiber D, deFilippi C, Hogan C, Diercks DB, Stein JC, Headden G, Limkakeng AT Jr, Anand I, Wu AHB, Papassotiriou J, Hartmann O, Ebmeyer S, Clopton P, Jaffe AS, Peacock WF (2013) Copeptin helps in the early detection of patients with acute myocardial infarction: primary results of the CHOPIN trial (Copeptin Helps in the early detection Of Patients with acute myocardial INfarction). J Am Coll Cardiol 62:150-160

69. O'Malley RG, Bonaca MP, Scirica BM et al (2014) Prognostic performance of multiple biomarkers in patients with non-STsegment elevation acute coronary syndrome: analysis from the MERLIN-TIMI 36 trial (Metabolic efficiency with ranolazine for less ischemia in non-ST-elevation acute coronary syndromesthrombolysis in myocardial infarction 36) [published correction appears in J Am Coll Cardiol. 2014 63:2642]. J Am Coll Cardiol. 63(16):1644-1653. https://doi.org/10.1016/j.jacc.2013.12.034

70. Morawiec B, Przywara-Chowaniec B, Muzyk P et al (2018) Combined use of high-sensitive cardiac troponin, copeptin, and the modified heart score for rapid evaluation of chest pain patients. Dis Markers. https://doi.org/10.1155/2018/9136971 (Published 2018 Nov 12)

71. von Haehling S, Papassotiriou J, Morgenthaler NG et al (2012) Copeptin as a prognostic factor for major adverse cardiovascular events in patients with coronary artery disease. Int J Cardiol 162:27-32. https://doi.org/10.1016/j.ijcard.2011.12.105

72. Potocki M, Reichlin T, Thalmann S et al (2012) Diagnostic and prognostic impact of copeptin and high-sensitivity cardiac troponin $\mathrm{T}$ in patients with pre-existing coronary artery disease and suspected acute myocardial infarction. Heart 98:558-565. https ://doi.org/10.1136/heartjnl-2011-301269

73. Lu J, Wang S, He G, Wang Y (2020) Prognostic value of copeptin in patients with acute coronary syndrome: a systematic review and meta-analysis. PLoS ONE 15:e0238288. https://doi.org/10.1371/ journal.pone.0238288 (Published 2020 Aug 28)

74. Zellweger C, Wildi K, Twerenbold R, Reichlin T, Naduvilekoot A, Neuhaus JD, Balmelli C, Gabutti M, Al Afify A, Ballarino P, Jäger C, Druey S, Hillinger P, Haaf P, Vilaplana C, Darbouret B, Ebmeyer S, Rubini Gimenez M, Moehring B, Osswald S, Mueller C (2015) Use of copeptin and high-sensitive cardiac troponin T for diagnosis and prognosis in patients with diabetes mellitus and suspected acute myocardial infarction. Int J Cardiol 190:190-197. https://doi.org/10.1016/j.ijcard.2015.04.134 (Epub 2015 Apr 17 PMID: 25920022)

75. Reiter M, Twerenbold R, Reichlin T, Mueller M, Hoeller R, Moehring B, Haaf P, Wildi K, Merk S, Bernhard D, Mueller CZ, Freese M, Freidank H, Campodarve Botet I, Mueller C (2013)
Heart-type fatty acid-binding protein in the early diagnosis of acute myocardial infarction. Heart 99:708-714. https://doi. org/10.1136/heartjnl-2012-303325 (Epub 2013 Mar 20 PMID: 23514979)

76. Thygesen K, Mair J, Mueller C, Huber K, Weber M, Plebani M, Hasin Y, Biasucci LM, Giannitsis E, Lindahl B, Koenig W, Tubaro M, Collinson P, Katus H, Galvani M, Venge P, Alpert JS, Hamm C, Jaffe AS, Study Group on Biomarkers in Cardiology of the ESC Working Group on Acute Cardiac Care (2012) Recommendations for the use of natriuretic peptides in acute cardiac care: a position statement from the Study Group on Biomarkers in Cardiology of the ESC Working Group on Acute Cardiac Care. Eur Heart J. 33:2001-2006. https://doi.org/10.1093/eurhe artj/ehq509 (Epub 2011 Feb 2 PMID: 21292681)

77. de Lemos JA, Morrow DA, Bentley JH, Omland T, Sabatine MS, McCabe CH, Hall C, Cannon CP, Braunwald E (2001) The prognostic value of B-type natriuretic peptide in patients with acute coronary syndromes. N Engl J Med 345:10141021

78. Morrow DA, de Lemos JA, Sabatine MS, Murphy SA, Demopoulos LA, DiBattiste PM, McCabe CH, Gibson CM, Cannon CP, Braunwald E (2003) Evaluation of B-type natriuretic peptide for risk assessment in unstable angina/non-STelevation myocardial infarction: B-type natriuretic peptide and prognosis in TACTICSTIMI 18. J Am Coll Cardiol 41:12641272

79. Widera C, Pencina MJ, Meisner A, Kempf T, Bethmann K, Marquardt I, Katus HA, Giannitsis E, Wollert KC (2012) Adjustment of the GRACE score by growth differentiation factor 15 enables a more accurate appreciation of risk in non-ST-elevation acute coronary syndrome. Eur Heart J 33:1095-1104. https://doi. org/10.1093/eurheartj/ehr444

80. Widera C, Pencina MJ, Bobadilla M, Reimann I, Guba-Quint A, Marquardt I, Bethmann K, Korf-Klingebiel M, Kempf T, Lichtinghagen R, Katus HA, Giannitsis E, Wollert KC (2013) Incremental prognostic value of biomarkers beyond the GRACE (Global Registry of Acute Coronary Events) score and high-sensitivity cardiac troponin $\mathrm{T}$ in non-ST-elevation acute coronary syndrome. Clin Chem 59:1497-1505. https://doi.org/10.1373/ clinchem.2013.206185 (Epub 2013)

81. Zelniker TA, Jarolim P, Silverman MG, Bohula EA, Park JG, Bonaca MP, Scirica BM, Morrow DA (2019) Prognostic role of GDF15 across the spectrum of clinical risk in patients with NSTEACS. Clin Chem Lab Med 57:1084-1092. https://doi.org/10.1515/ cclm-2018-1081 (PMID: 30710475)

82. Möckel M (2020) One fits all hs troponin or more personalized dual markers strategies in the primary diagnostic assessment of patients with suspected acute coronary syndrome? Biomarkers 25:611-612. https://doi.org/10.1080/1354750X.2020.1841293 (Epub 2020 Nov 24 PMID: 33175594) 